\title{
Primary Fallopian Tube Carcinoma: Case Report of Rare Malignancy
}

\author{
Dr. Parul Garg MD*, Dr. Sarita Nibhoria MD, Dr. Shilpa Pal MBBS, Dr. Navjot Kaur MBBS, Dr.Bikramjit Singh MBBS
}

Baba Farid University of Health Science, Sadiq Road, Society Nagar, Faridkot, Punjab 151203, India

DOI: $10.36347 /$ sjams.2021.v09i02.022

| Received: 18.01.2021 | Accepted: 02.02.2021 | Published: 28.02.2021

*Corresponding author: Dr. Parul Garg

Abstract

Primary fallopian tube carcinoma is an extremely uncommon tumor of female genital tract origin. Histologically and clinically it resembles the epithelial ovarian cancer. Due to its nonspecific symptomatology and rarity of this neoplasm, correct preoperative diagnosis is made only in $4 \%$ of the cases and is usually first recognized by pathologist. We hereby present a case of primary fallopian tube carcinoma. A 42-year-old female who presented with intermittent vaginal bleeding, lower abdominal pain, and pelvic mass. On physical examination, lower abdominal tenderness was present. The clinical and radiological findings suggested adnexal tumor with elevated CA-125 levels. The patient underwent total abdominal hysterectomy with bilateral salpingo-oophorectomy. On histopathology a diagnosis of High grade serous carcinoma of the fallopian tube was given. This case is being reported due to the scarcity of data published from the Indian population and rarity of this neoplasm.

Keywords: cancer, Primary fallopian tube carcinoma, CA-125 levels.

Copyright $\odot 2021$ The Author(s): This is an open-access article distributed under the terms of the Creative Commons Attribution 4.0 International License (CC BY-NC 4.0) which permits unrestricted use, distribution, and reproduction in any medium for non-commercial use provided the original author and source are credited.

\section{INTRODUCTION}

Primary fallopian tube carcinoma (PFTC) is a rare gynecological tumor accounting for an approximately $0.14 \%-1.8 \%$ of female genital tract malignancies $[1,2]$. It was first described by Renaud in 1847. In 1888, Orthmann presented the first case report [3]. PFTC is rarely diagnosed preoperatively due to its nonspecific symptomatology [4]. The etiology of this cancer is not known; its association with infertility, tuberculous salpingitis, chronic tubal inflammation, infertility, and tubal endometriosis has been reported [5]. An ovarian and fallopian tube malignancy shared similar BRCA germline and TP53 mutations [6].

\section{Case Report}

A 42-year-old female came in gynaecological department with clinical features of abnormal vaginal bleeding and lower abdominal pain which was dull in nature with no significant family history. On physical examination, she had lower abdominal tenderness. Per speculum examination revealed mild vaginal bleeding with healthy cervix and vagina. Transabdominal sonography revealed a adnexal mass .The patient after an informed consent underwent total abdominal hysterectomy with bilateral salpingo-oopherectomy. Specimens was received in histopathology laboratory.

Gross examination- Uterus with cervix measured $8 \mathrm{~cm} \times 6 \mathrm{~cm} \times 4 \mathrm{~cm}$. Myometrial thickness ranges from 2 to $2.5 \mathrm{~cm}$. Cut section cervix- nabothian cyst identified. Right fallopian tube measured $5 \mathrm{~cm}$. Cut section fallopian tube revealed gray-white growth identified occluding the lumen of fallopian tube measuring $2 \times 1 \times 0.3 \mathrm{~cm}$. Left fallopian tube measures $2 \mathrm{~cm}$ in length. Cut section- unremarkable.

Microscopic Examination- Right fallopian tube showed lining epithelium with wall displaying infiltrating tumor composed of atypical epithelial cells with moderate degree of nuclear pleomorphism. The individual tumor cells have high $\mathrm{N}$ : $\mathrm{C}$ ratio, round to oval nuclei, vesicular chromatin, prominent nucleoli arranged in glandular pattern, and forming papillae at places along with mitotic figures. Other fallopian tube is unremarkable. Sections from both the ovaries were unremarkable. Histopathological diagnosis of High Grade Serous Adenocarcinoma of fallopian tube was made. Endometrium showed proliferative phase, myometrium showed foci of Adenomyosis. Both ovaries were unremarkable. 
Parul Garg et al; Sch J App Med Sci, Feb, 2021; 9(2): 291-293

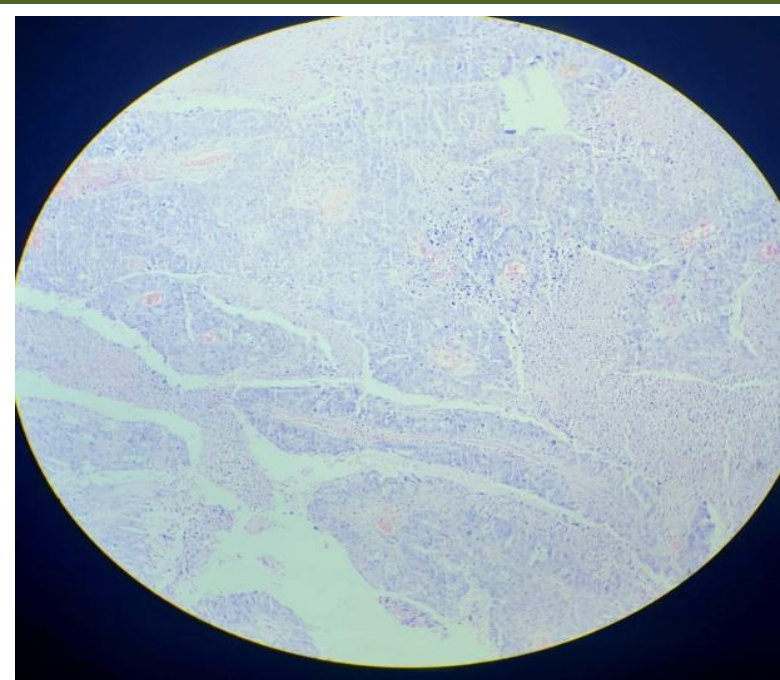

Fig-1: Scanner view showing wall of fallopian tube displaying features of primary serous adenocarcinoma. $\mathrm{H}$ and $\mathrm{E}$ stain, $40 \mathrm{X}$

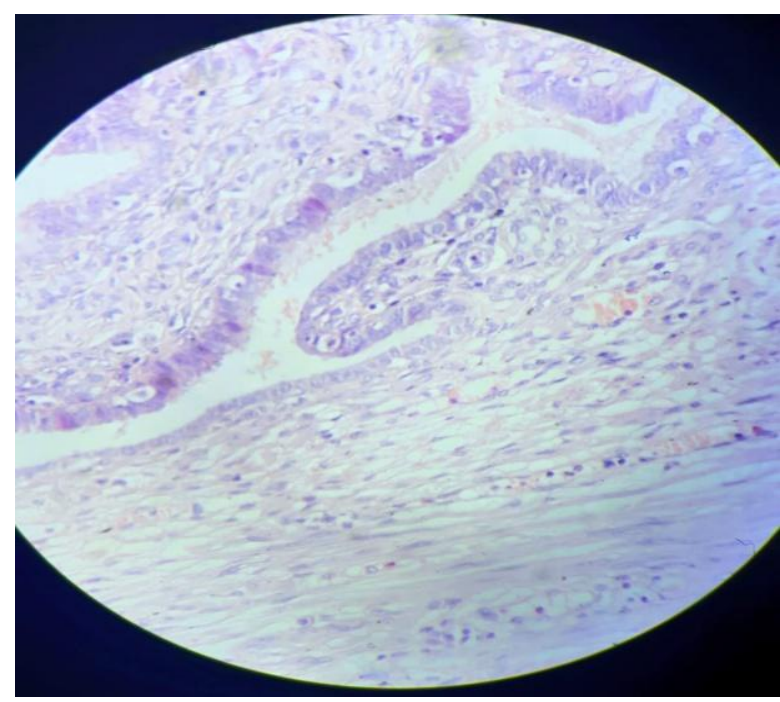

Fig-2: Low-power view displaying tumor cells arranged in glandular pattern. $\mathrm{H}$ and $\mathrm{E}$ stain, 100X

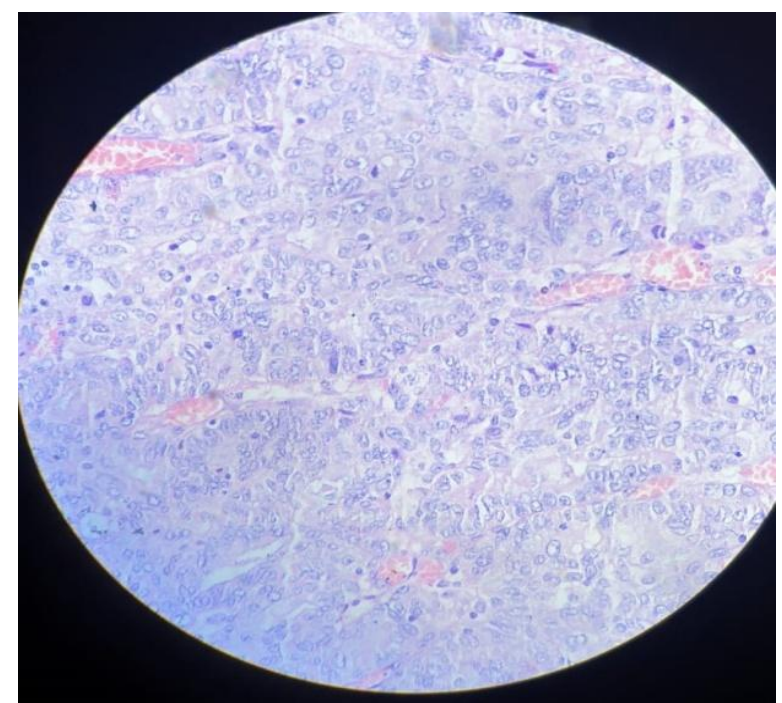

Fig-3: High power view showing individual tumor cells. $H$ and $\mathrm{E}$ stain, 400X
Immunohistochemical findings are: The malignant cells are positive for CK7, WT1, PAX8 and negative for CK20.

In this case, the diagnosis was arrived after histopathological examination. This is the fact that fallopian tube carcinomas are almost difficult to diagnose preoperatively due to its rarity and nonspecific symptomatology.[7] The patient was discharged after a week following surgery and was referred to oncologist for adjuvant therapy.

\section{DISCUSSION}

PFTC is the rarest tumor of the female genital tract and was first reported in literature 1897 [8]. PFTC most commonly occurs in the postmenopausal age group with peak incidence in-between age 60 and 64 years and the mean age of incidence as 55 years (age range: $17-88$ years) [9]. In the present case, age of the patient was 42-year old.

The clinical presentation of PFTC is usually nonspecific. The Latzko's triad of typical symptoms are intermittent profuse serosanguinous vaginal bleeding, colicky pain relieved by discharge and an abdominal or pelvic mass. The triad has been documented in only $15 \%$ of PFTC cases [10]. Pathogenesis of fallopian tube serous cystadenocarcinoma is poorly understood. If the definitive oncogenic driver can be found out and confirmed through robust studies, gene-targeted therapy can be targeted [11].

The diagnostic criteria for PFTC were first established by $\mathrm{Hu}$ et al. and later slightly modified by sidles. It is difficult to differentiate PFTC from epithelial ovarian carcinoma. The patients should meet at least one of the following criteria for the diagnosis of PFTC [4]. (a) The main tumor is in the tube and it arises from the endosalpinx; (b) histologically, the pattern reproduces the epithelium of the mucosa and it often shows a papillary pattern; (c) if the wall is involved, the transition between the benign and the malignant epithelium should be demonstrable; and (d) the ovaries and the endometrium are either normal or they may contain less tumor than that which is there in the tube. In our case, all the four criteria were fulfilled.

Routine imaging modalities for suspected gynecological malignancy are ultrasound of whole abdomen and pelvis, computed tomography (CT scan), or magnetic resonance imaging (MRI) of the abdomen. Transabdominal and transvaginal ultrasound is the initial and essential imaging investigation for diagnostic workup of the patient with other pelvic suspected tubal pathology. However, ultrasound finding of tubal carcinoma may mimic other pelvic conditions such as ovarian tumor and tubo-ovarian abscess; however, several other findings may provide diagnostic clue preoperatively. On CT scan, a solid papillary intratubal mass allows easy detection of PFTC. MRI is considered 
Parul Garg et al; Sch J App Med Sci, Feb, 2021; 9(2): 291-293

a better method than CT scan or ultrasound for detecting the infiltrating tumor [4].

The surgical procedure of choice is total abdominal hysterectomy, bilateral salpingooophorectomy, selective pelvic, and para-aortic lymphadenectomy depends on the stage of PFTC. Given the early lymphatic spread, the role of the routine lymph node evaluation is advised in PFTC. In our case, the patient after informed consent underwent total abdominal hysterectomy with bilateral salpingooophorectomy with intraoperative inspection of lymph node which was grossly insignificant; postoperative platinum-based combination adjuvant chemotherapy is the most commonly used therapy for PFTC [12].

\section{CONCLUSION}

The incidence of PFTC is rather low accounting for $0.1 \%-1.8 \%$ of all genital malignancies. Due to nonspecific symptomatology, it is very difficult to diagnose preoperatively. In most cases, it is a histopathological diagnosis. Hence, it should be considered in differential diagnosis of pre and postmenopausal women who presented with unexplained uterine bleeding, pelvic pain, and adnexal mass. Because of its histopathological similarities with ovarian cancer, its treatment is similar to that of the latter.

\section{REFERENCES}

1. Balaya V, Metzger U, Denet C, Herry M, Lecuru F. Isolated fallopian tube metastasis from colorectal cancer: Ultrasonographic features. J Ultrasound. 2018; 21:69-75.

2. Toyoda $T$, Suzuki H, Nakajima $T$, Iwata $T$, Matsuoka A, Nishikimi K, et al. Successful diagnosis of an occult fallopian tube carcinoma detected from the diaphragm metastasis. Gen Thorac Cardiovasc Surg. 2018; 66:484-7.

3. Chen Y, Ling C, Bian C. Port-site metastasis as a primary complication following diagnostic laparoscopy of fallopian tube carcinoma: A case report. Medicine (Baltimore) 2018; 97:e11166.
4. Rexhepi M, Trajkovska E, Ismaili H, Besimi F, Rufati N. Primary fallopian tube carcinoma: A case report and literature review. Open Access Maced J Med Sci. 2017; 5:344-8.

5. Hariprasad P, Hariprasad S, Srinivas T, Shetty KJ. Primary bilateral fallopian tube carcinoma the report of a single case with review of the literature. J Clin Diagn Res. 2013; 7:930-2.

6. Howitt BE, Hanamornroongruang S, Lin DI, Conner JE, Schulte S, Horowitz N, Crum CP, Meserve EE. Evidence for a dualistic model of high-grade serous carcinoma: BRCA mutation status, histology, and tubal intraepithelial carcinoma. The American journal of surgical pathology. 2015 Mar 1;39(3):287-93.

7. Puig F, Lapresta M, Lanzon A, Crespo R. Fallopian tube carcinoma: Incidental finding during surgery for acute pelvic inflammatory disease - Case report. Eur J Gynaecol Oncol. 2006; 27:526-7.

8. Tongsong $\mathrm{T}$, Wanapirak $\mathrm{C}$, Tantipalakorn $\mathrm{C}$, Tinnangwattana D. Sonographic diagnosis of tubal cancer with IOTA simple rules plus pattern recognition Asian Pac J Cancer Prev. 2017;18:3011-5.

9. Manjunatha HK, Mohan B, Geethamani V. Bilateral primary papillary serous carcinoma of the fallopian tube. J Clin Diagn Res. 2017; 11:ED38-9.

10. Lau HY, Chen YJ, Yen MS, Chen RF, Yeh SO, Twu NF. Primary fallopian tube carcinoma: a clinicopathologic analysis and literature review. Journal of the Chinese Medical Association. 2013 Oct 1;76(10):583-7.

11. Kristeleit R, Shapiro GI, Burris HA, Oza AM, LoRusso P, Patel MR, Domchek SM, Balmaña J, Drew Y, Chen LM, Safra T. A phase I-II study of the oral PARP inhibitor rucaparib in patients with germline BRCA1/2-mutated ovarian carcinoma or other solid tumors. Clinical Cancer Research. 2017 Aug 1;23(15):4095-106.

12. Berek JS, Crum C, Friedlander M. Cancer of the ovary, fallopian tube, and peritoneum. Int $\mathrm{J}$ Gynaecol Obstet. 2015; 131 Suppl 2:S111-22. 